\title{
Resources for Educating, Training, and Mentoring Nurses and Unregulated Nursing Care Providers in Palliative Care: A Review and Expert Consultation
}

\author{
Barbara Pesut, PhD, RN ${ }^{1}$ and Madeleine Greig, BSN, RN²
}

\begin{abstract}
Background: Nurses and nursing care providers provide the most direct care to patients at end of life. Yet, evidence indicates that many feel ill-prepared for the complexity of palliative care.

Objective: To review the resources required to ensure adequate education, training, and mentorship for nurses and nursing care providers who care for Canadians experiencing life-limiting illness and their families.

Methods: This is a systematic search and narrative review in the Canadian context.

Results: Six previous reviews and 26 primary studies were identified. Studies focusing on regulated nurses indicated that even amid variability in content, delivery methods, and duration, palliative education improves nurses' knowledge, confidence, attitudes, and communication abilities, and decreases nurses' stress. Results from palliative education in undergraduate curriculum were less definitive. However, studies on palliative simulation in undergraduate education suggest that it improves knowledge and confidence. Studies focusing on educating nursing care providers, either alone or in collaboration with regulated nurses, indicated positive outcomes in knowledge, confidence, communication, identification of clients who are dying, abilities to interact with patients and families, and a better understanding of their own contributions to care. Curricular resources in Canada have been developed. However, there is no dedicated and funded capacity-building strategy.

Discussion: Resources exist to support palliative education for nurses and nursing care providers. Furthermore, the evidence suggests good outcomes from this education. However, there is no dedicated strategy for implementing those resources. Furthermore, there is little evidence of the critical role of knowledge translation in preparing nurses and nursing care providers for evidence-informed palliative practice.
\end{abstract}

Keywords: education; healthcare assistants; nursing; palliative; review

\section{Background}

$\mathbf{N}$ URSES ARE FRONTLINE CARE PROVIDERS for patients and families at end of life. Unregulated nursing care providers, who are variously referred to as healthcare assistants, healthcare workers, home health aides, or home support workers, also play a central role. These providers care for increasingly complex patients who are dying at home and in residential care. The achievement of high-quality palliative care for all Canadians cannot be achieved without adequate preparation of these frontline healthcare providers. Studies consistently indicate a need for further palliative care education for nurses and nursing care providers who are working across settings of care. ${ }^{1-5}$ Therefore, the objective of this article is to review the resources required to ensure adequate education, training, and mentorship for nurses and nursing care providers who care for Canadians experiencing lifelimiting illness and their families.

\section{Methods}

The systematic retrieval of primary studies and gray literature was conducted according to the process outlined in Sims (under review). For evidence related to regulated nurses, searches were limited to articles published between 2012 and 2016, as a scoping review of the evidence (2001-2011)

\footnotetext{
${ }^{1}$ Canada Research Chair, Health, Ethics and Diversity, Faculty of Health and Social Development, University of British Columbia, Okanagan, Kelowna, British Columbia, Canada.

${ }^{2}$ Faculty of Health and Social Development, School of Nursing, University of British Columbia, Okanagan, Kelowna, British Columbia, Canada. Accepted September 20, 2017.
} 
on palliative care education for nurses was published in 2014. ${ }^{6}$ For evidence specific to unregulated nursing care providers, searches were inclusive of articles published between 2006 and 2016. Studies were included if they focused on educating nurses or nursing care providers in palliative care, and if they included a systematic evaluation of that education. Exclusion criteria were any studies that focused strictly on specialty areas, such as oncology, geriatrics, pediatrics, critical care, and/or heart failure; did not disaggregate nursing outcomes from medicine or allied health; or whether they focused only on assessing the training needs or preparedness of nurses around palliative care. Grey literature was included if it directly addressed the question of preparation and mentorship of nurses and nursing care providers in the Canadian context.

This review also used expert consultation to identify key Canadian resources relevant to the preparation and mentorship of nurses and nursing care providers. Experts included representatives from organizations who provide palliative care education (e.g., Canadian Hospice Palliative Care Association, Pallium Canada, Life and Death Matters) and a British Columbia-based policy/practice team, called iPANEL, which is focused on implementing a palliative approach in nursing (see www.ipanel.ca for further information). Consultation with these experts led to the identification of additional key documents to inform this review.

\section{Findings}

Review findings will be reported in relation to evidence about the effectiveness of palliative education, and the resources available to educate nurses and nursing care providers.

\section{Effectiveness of palliative education}

Twenty-six primary studies addressed palliative education effectiveness. For a description of countries of studies' origins, an overview of study designs, and an outline of studies' research contexts, see Tables 1-3, respectively. Six previous reviews pertinent to the topic were also identified. ${ }^{6-11}$ Results from $^{-1}$ these reviews will be reported as part of the body of findings.

A review published in 2014 of the evidence on educating nurses for palliative care identified 58 studies published between 2001 and $2011 .^{6}$ Studies reviewed demonstrated variability in the curricula used and duration of the education (e.g., 1-131 hours). Despite this variability, $86 \%$ of the studies reported positive outcomes. A meta-analysis conducted of 9 different outcomes from these 58 studies indicated large effects on nurses' stress; moderate effects on nurses' communication, attitude, knowledge, and confidence;

Table 1. Countries of Studies' Origins

\begin{tabular}{lc}
\hline Country & Number of contributions, $\mathrm{n}(\%)$ \\
\hline United States & $10(38.5)$ \\
United Kingdom & $8(30.8)$ \\
Canada & $4(15.4)$ \\
Australia & $1(3.8)$ \\
New Zealand & $1(3.8)$ \\
Belgium & $1(3.8)$ \\
Sweden & $1(3.8)$ \\
\hline
\end{tabular}

Table 2. Study Design

\begin{tabular}{lc}
\hline Study design & Number of studies, $\mathrm{n}(\%)$ \\
\hline Mixed-method design & $13(50.0)$ \\
Quantitative design & $7(26.9)$ \\
Qualitative design & $5(19.2)$ \\
Curricular evaluation & $1(3.8)$ \\
\hline
\end{tabular}

and small effects on nurses' anxiety, perceptions, work environment, and changes in practice. However, few studies in this review examined outcomes beyond the level of the individual nurse. Furthermore, many of the studies reviewed had methodological limitations, which means that the findings must be viewed cautiously.

We identified a further six studies published since the 2014 review. Barrere and Durkin ${ }^{12}$ studied the experiences of nurses one year after graduating from an undergraduate nursing program that incorporated palliative curriculum from the United States End-of-Life Nursing Education Consortium (ELNEC). Although these newly graduated nurses had learnt important palliative content, they identified the importance of mentorship, support, and real-world experience in enhancing their confidence in providing palliative care. Other studies reported positive gains from implementing practice-support tools, ${ }^{13}$ an online course for nurse practitioners, ${ }^{14}$ an online course for nurses that used individualized learning, ${ }^{15}$ and education that used an interprofessional approach in residential care. ${ }^{16}$ One innovative study, designed to enhance the capacity of palliative home care nurses to support the workplace learning of general practitioners, indicated positive gains in interprofessional learning and practice. ${ }^{17}$ This is an important finding, because although home care nurses regularly find themselves in the role of informally educating general practitioners about palliative care, that role is rarely acknowledged or supported.

A review published in 2012 specific to continuing professional development programs in palliative care for rural nurses identified 10 studies. ${ }^{7}$ Although definitive recommendations could not be made based on the available evidence, the authors concluded that little evidence exists about the effectiveness of online learning that rural nurses prefer face to face multidisciplinary learning, and that rural nurses face many barriers such as heavy workloads, limited learning opportunities, and challenges attending education at a distance.

Three reviews of palliative care education in undergraduate nursing education were retrieved: two focusing on generic palliative education $^{8,9}$ and one specific to simulation in the context of palliative care. ${ }^{10}$ The two generic reviews, both published in 2014, reported on 17 and 18 studies, respectively, with $\sim 30 \%$ overlap in the studies identified. Both

Table 3. Study Context

\begin{tabular}{lc}
\hline Study context & Number of studies, $\mathrm{n}(\%)$ \\
\hline Residential & $9(34.6)$ \\
University/college & $6(23.1)$ \\
Community & $5(19.2)$ \\
Various & $3(11.5)$ \\
Acute/teaching hospitals & $2(7.7)$ \\
Unknown & $1(3.8)$ \\
\hline
\end{tabular}


reviews reported a high degree of experiential learning strategies (e.g., reflection on practice and engagement through media) in palliative undergraduate education, which resulted in variable learning outcomes. Study authors suggested that methods by which to evaluate experiential learning are lacking, which could explain the mixed outcome findings. Authors further reported that in undergraduate education, palliative content is typically integrated throughout the curriculum or offered as a stand-alone upper year elective. The amount of time dedicated to palliative content ranged from 2 to 50 hours across programs. ${ }^{8}$ Authors of one review highlighted the importance of paying attention to readiness factors when introducing palliative content such as the level of student and individual student characteristics, including their experiences with death. ${ }^{9}$ Two additional studies published since these reviews reported that case-based learning ${ }^{18}$ and apprenticeship-style education $^{19}$ enhanced student preparedness for palliative care. The review of simulation in undergraduate nursing education ( $n=6$ studies) concluded that simulation may increase students' knowledge, confidence, and satisfaction, as long as strategies to support students' psychological safety (e.g., debriefing) are used. ${ }^{10}$ These findings were echoed in two additional studies published after the review. ${ }^{20,21}$

The evidence related to the preparation of nursing care providers for palliative care was less robust. One systematic review, published in 2016, focused on end-of-life education specific to nursing home staff. ${ }^{11}$ Similar to findings of previous reviews cited in this article, this review highlighted problems with study methodologies and the lack of evidence on patient or system level outcomes. Beyond this review, we located eight primary studies that focused specifically on educating nursing care providers for palliative care ${ }^{22-29}$ and six publications, representing five studies, that explored the effectiveness of education provided jointly to nurses and nursing care providers. ${ }^{30-35}$

Innovations within this literature included collaborative curriculum, grounded in a palliative approach, for nurses and nursing care providers, ${ }^{32}$ an educational intervention designed to raise staff awareness of palliative care, ${ }^{33}$ and the use of reflective debriefing groups after patient deaths. ${ }^{34}$ Evidence from these studies indicated that nursing care providers realized substantial knowledge gains both from education targeted specifically to their needs ${ }^{23,27,29}$ and in the context of collaborative education. ${ }^{30,35}$ One study suggested that these improvements in knowledge were most evident in staff who attended three or more inservices. ${ }^{31}$ This is an important finding when the length of education varies greatly in the literature.

Across these studies, palliative education had numerous benefits for nursing care providers, including better understanding of roles and knowledge, increased confidence in communicating within the healthcare team, more responsibility for identifying those on a dying trajectory, enhanced abilities to interact with patients and families, better understanding of their own contributions to care, and a greater familiarity with tools relevant to palliative care. ${ }^{2,25,29,35}$ In the context of collaborative education for nurses and nursing care providers, nurses too reported better abilities to communicate with their nursing care provider colleagues. The knowledge gains they reported were generally not statistically significant, whereas the gains reported by the nursing care providers were. ${ }^{35}$ When designing collaborative education, nursing care providers will be more successful if they receive some baseline knowledge in palliative care before the educational session, if they are oriented to unfamiliar learning strategies (e.g., problem-based), and if the content strategically builds upon their unique knowledge. ${ }^{32}$ Nursing care providers develop significant expertise as a result of caring for many on a dying trajectory over prolonged periods of time.

A few studies focused on developing computer-based or blended learning training programs for nursing care providers with good outcomes. ${ }^{24,26,29}$ In one Canadian study, nursing care providers who shadowed hospice staff as part of an experiential learning opportunity reported positive gains in their understanding of palliative care. ${ }^{28}$ Another Canadian study reported on an educational innovation designed to provide collaborative learning experiences between registered nursing and nursing care provider students with a focus on a palliative approach for community-dwelling clients. ${ }^{36} \mathrm{Al}-$ though students initially reported gains in knowledge and confidence, not all gains were sustained until the three-month postmeasurement interval. Overall, there is little evidence examining the effectiveness of palliative education on nursing care providers. Nevertheless, the available evidence suggests that diverse educational approaches produce substantial gains in nursing care providers' knowledge and confidence.

\section{Educational resources}

One of the most notable aspects of the evidence reviewed was the diversity in what constituted palliative educational content and the time devoted to that content. One of the ways to standardize such diversity is to create educational resources such as standards of practice, competency frameworks, and curriculum. A number of Canadian resources have been developed to support palliative education. A 2012 review of international palliative care competency frameworks identified 11 nursing frameworks, two of which have been developed in Canada. ${ }^{37}$ The Canadian Hospice Palliative Care Association has developed standards of practice, and other resources, to support specialty nursing certification in hospice palliative care. ${ }^{38-40}$ This certification is available through the Canadian Nurses Association. ${ }^{41}$ As of July 2015, 1348 Canadian nurses held this specialty designation. To support the integration of palliative care into entry-level nursing education, the Canadian Association of Schools of Nursing has developed palliative care competencies and integration tools to support curricular development. ${ }^{42, *}$

Palliative standards and competencies for nursing care providers exist both nationally and provincially. They are, though, embedded within generic educational competencies and have varying degrees of specificity. ${ }^{43,44}$ There are also Canadian-based curricula, which build upon these competencies, to prepare nursing care providers specifically for palliative care. ${ }^{45,46}$ In addition, personal support worker competencies have been developed for palliative care in longterm care. ${ }^{47, \dagger}$ We were unable to locate a palliative-specific

\footnotetext{
*It is important to note that in Canada, provincial nursing regulatory bodies also develop standards of practice and competencies related to palliative care as part of their generalist entry-level practice requirements.

${ }^{\top}$ This is just one example. A number of initiatives in Canada are focusing on the development of nursing care providers
} 
competency document, similar to the one developed in Ireland, whereby competencies for nursing care providers are delineated within a comprehensive multidisciplinary palliative care competency document. ${ }^{48}$

The literature contains numerous descriptions of curricula designed to educate nurses and nursing care providers in palliative care. ${ }^{49-51}$ The most well researched of these curricula is from the ELNEC in the United States. These trainthe-trainer workshops, initiated in 2000 and funded by the Robert Wood Johnson Foundation, have been attended by 19,500 nurses and other healthcare professionals. Recipients of the training are responsible for integrating knowledge from the curriculum into their own workplaces. In 2006, the first ELNEC international curriculum was launched. Since that time, it has been offered in eight languages to individuals from 85 countries. ${ }^{52}$ Canada does not have a similar national initiative dedicated and funded to developing nursing capacity. However, the LEAP (Learning Essential Approach to Palliative Care) program available through Pallium Canada is a competency-based curriculum that has been adapted to various settings of care and disease conditions (e.g., longterm care and cancer) that includes nursing and nursing care providers as part of the interdisciplinary team.

\section{Discussion}

This review identified a robust body of evidence about the impact of palliative education on nurse outcomes. Participating in palliative education reduces nurses' stress, and enhances their communication, attitudes, knowledge, and confidence in caring for palliative clients. Less is known about the sustainability of those gains, about point of practice change, or about patient and system level outcomes. The impact of educational approaches used in undergraduate education, such as experiential learning, is less clear. However, this may be an artifact of finding ways to properly evaluate this type of learning. Studies that focused on simulation as a palliative learning strategy in undergraduate education showed more promising results.

Fewer studies have focused on preparing nursing care providers for palliative care, despite the important role they play for palliative clients and families both at home and in residential care. Studies that have been done suggest that education improves nursing care providers' self-reported knowledge, confidence, and attitudes. Collaborative approaches that educate nursing care providers alongside other members of the team may be particularly effective, as long as nursing care providers receive some baseline preparation that facilitates their abilities to engage confidently in the learning environment.

This review also identified a number of important resources for supporting palliative education, including competency documents, standards of practice, and curricula. Indeed, the challenge may lie in identifying the best resources to support practice amid the number of available options. This is particularly true when there is no integrated competency document that provides a guide for unique and shared scopes of practice among the various multidisciplinary care providers. Despite these resources, a coordinated and funded effort to develop capacity, and to monitor system level achievement of that capacity, seems to be lacking. Although there are dedicated pockets of excellence, there is no national strategy that is resourced to develop the capacity of nurses and nursing care providers similar to what has been developed in other countries. This may mean that these resources are not being used to their maximum effect.

Despite the resources identified within this review, it is important to emphasize that high-quality preparation for palliative care is not just about the delivery of knowledge through education. The educational process cannot be considered apart from the factors that will influence the adaptation, uptake, and application of that knowledge. ${ }^{53,54}$ For example, in the review conducted here, nursing care providers identified a number of organizational factors that inhibited their abilities to apply the palliative knowledge they had gained from educational initiatives. These included heavy workloads, challenging communication, limited opportunities to discuss care, interpersonal tensions, and lack of personal support when they had to cope with multiple deaths. ${ }^{22,27,29,32}$ These factors that influence learners' abilities to apply the knowledge gained elucidate why knowledge translation is essential to any consideration of necessary resources for education, training, and mentorship in palliative care.

Knowledge translation is about ensuring that palliative care knowledge is adapted and applied in every setting of care where people die, including the home, residential care, and acute care. Ironically, there is a preponderance of evidence pointing to the problematic nature of dying in these very settings where individuals are most likely to die. ${ }^{55,56}$ Yet, there is little available in the literature to guide adaptations in palliative education to suit care settings such as residential care, acute hospital units, or rural and remote locations. For example, how might palliative care practices, designed to be enacted within specialized palliative teams and units, need to be adapted for the nurse who works alone in a remote locale? Furthermore, few studies focus on modifying the work environment, including providing mentorship, so that the principles and practices that are taught within palliative education can be realized. Appropriate workloads, practice support tools, and strategies to support effective communication are vital resources to enable nurses to apply palliative care knowledge. ${ }^{57}$

The need to contextualize and adapt palliative care education is best embodied in the idea of a palliative approach to care. ${ }^{*}$ A recent knowledge synthesis ${ }^{57}$ conducted to delineate key aspects of a palliative approach indicated that it takes an "upstream orientation" for those with life-limiting conditions, adapts palliative care knowledge and expertise, and is integrated into systems of care that do not specialize in palliative care. (p.1) Therefore, effective educational strategies take palliative care knowledge and adapt it to (1) early support for those on a dying trajectory; (2) a variety of lifelimiting conditions beyond cancer; and (3) settings of care such a home care, residential care, acute care, and rural care. For example, a nurse caring for a person living with heart failure must first recognize that they are on a dying trajectory and then know how to integrate chronic illness selfmanagement strategies with supportive conversations around goals of care. ${ }^{58}$ This requires knowledge both of palliative

\footnotetext{
British Columbia has a policy/practice initiative aimed at integrating a palliative approach for nursing called "Initiative for a Palliative Approach: Nursing Evidence and Leadership. See www. ipanel.ca for further information.
} 
symptom management and of cardiac symptom management appropriate to the transition stage. Furthermore, this knowledge needs to be contextualized within the available resources as the person transitions between sites of care. This includes practice support tools and communication structures to support care integration. ${ }^{57}$ Effective knowledge translation, which entails due attention to context and adaptation, is essential to supporting nurses and nursing care providers in achieving high-quality palliative care for all Canadians.

\section{Conclusion}

This review was conducted to identify the resources required to educate, train, and mentor nurses and nursing care providers in palliative care. Standards, competencies, and curricula exist for both nurses and nursing care providers in Canada. Furthermore, evidence suggests that palliative education results in positive outcomes for nurses and nursing care providers, even when that education varies in content, duration, and delivery. However, the important resource of a dedicated and funded strategy to build nursing capacity in palliative care is missing. Furthermore, little attention has been paid to the importance of knowledge translation as it applies to palliative education. There is a critical need to adapt and contextualize palliative knowledge and to create patient care settings that are conducive to the enactment of that knowledge.

\section{Acknowledgments}

The authors would like to thank the experts who gave of their time to inform this review. Special thanks to Sharon Baxter from the Canadian Hospice Palliative Care Association, Kathryn Downer from Pallium Canada, Katherine Murray from Life and Death Matters, and Patricia Porterfield. The authors also acknowledge the contributions of the Palliative Care Matters Research Support Team: Sharna Polard and Roger Salus for library services and literature searching; Heather Stiles and Michelle Sims for overall research coordination and assistance; and Lisa Weisgerber for literature screening, literature review, and project support.

\section{Author Disclosure Statement}

MG received financial remuneration for this report, generously provided by the Canada Research Chair's program. The authors have no conflicts of interest to disclose.

\section{References}

1. Brazil K, Brink P, Kaasalainen S, et al.: Knowledge and perceived competence among nurses caring for the dying in long-term care homes. Int J Palliat Nurs 2012;18:77-83.

2. McDonnell MM, McGuigan E, McElhinney J, et al.: An analysis of the palliative care education needs of RGNs and healthcare assistants in nursing homes in Ireland. Int $\mathbf{J}$ Palliat Nurs 2009;15:448-455.

3. Eriksson G, Bergstedt TW, Melin-Johansson C: The need for palliative care education, support, and reflection among rural nurses and other staff: A quantitative study. Palliat Support Care 2015;13:265-274.

4. Sawatzky R, Roberts D, Reimer-Kirkham S, et al.: Integration of a Palliative Approach in Home, Acute medical, and Residential Care Settings: Findings from a ProvinceWide Survey. Victoria, BC. 2015. https://figshare.com/ articles/Integration_of_a_Palliative_Approach_in_Home_ Acute_Medical_and_Residential_Care_Settings_Findings_ From_a_Province_Wide_Survey/1455949 (last accessed June 23, 2017).

5. Ingleton $\mathrm{C}$, Gardiner $\mathrm{C}$, Seymour JE, et al.: Exploring education and training needs among the palliative care workforce. BMJ Support Palliat Care 2013;3:207-212.

6. Pesut B, Sawatzky R, Stajduhar K, et al.: Educating nurses for palliative care: A scoping review. J Hosp Palliat Nurs 2014;16:47-54.

7. Phillips JL, Piza M, Ingham J: Continuing professional development programmes for rural nurses involved in palliative care delivery: An integrative review. Nurse Educ Today 2012;32:385-392.

8. Bassah N, Seymour J, Cox K: A modified systematic review of research evidence about education for pre-registration nurses in palliative care. BMC Palliat Care 2014;13:56.

9. Gillan PC, van der Riet PJ, Jeong S: End of life care education, past and present: A review of the literature. Nurse Educ Today 2014;34:331-342.

10. Gillan PC, Jeong S, van der Riet PJ: End of life care simulation: A review of the literature. Nurse Educ Today 2014;34:766-774.

11. Anstey S, Powell T, Coles B, et al.: Education and training to enhance end-of-life care for nursing home staff: A systematic literature review. BMJ Support Palliat Care 2016;6:353-361.

12. Barrere $C$, Durkin A: Finding the right words: The experience of new nurses after ELNEC education integration into a BSN curriculum. Medsurg Nurs 2014;53:35-43.

13. Clark K, Curry T, Byfieldt N: The effect of a care bundle on nursing staff when caring for the dying. Int $\mathrm{J}$ Palliat Nurs 2015;21:292-298.

14. Letizia M, Jones T: An educational intervention for nurse practitioners providing palliative care in nursing homes. $\mathbf{J}$ Hosp Palliat Nurs 2012;14:351-357.

15. Wheeler C, Anstey S, Lewis M, et al.: The effect of education on community nursing practice in improving the partient-carer experience at the end of life. B J Community Nurs 2014;19:284-290.

16. Henning $\mathrm{M}, \mathrm{Hu} \mathrm{J}$, Webster $\mathrm{C}$, et al.: An evaluation of Hospice New Zealand's interprofessional fundamentals of palliative care program at a single site. Palliat Support Care 2015; 13:725-732.

17. Pype P, Mertens F, Wens J, et al.: Preparing palliative home care nurses to act as facilitators for physicians' learning: Evaluation of a training programme. Palliat Med 2015;29:458-463.

18. Bailey C, Hewison A: The impact of a 'Critical Moments' workshop on undergraduate nursing students' attitudes to caring for patients at the end of life: An evaluation. J Clin Nurs 2014;23:3555-3563.

19. Hold JL, Blake BJ, Ward EN: Perceptions and experiences of nursing students enrolled in a palliative and end-of-life nursing elective: A qualitative study. Nurse Educ Today 2015; 35:777-781.

20. Lewis C, Reid J, McLernon Z, et al.: The impact of a simulated intervention on attitudes of undergraduate nursing and medical students towards end of life care provision. BMC Palliat Care 2016;15:67.

21. Fluharty L, Hayes AS, Milgrom L, et al.: A multisite, multi-academic track evaluation of end-of-life simulation for nursing education. Clin Simul Nurs 2012;8:e135-e143. 
22. Beck I, Tornquist A, Edberg A: Nurse assistants' experience of an intervention focused on a palliative care approach for older people in residential care. Int $\mathrm{J}$ Older People Nurs 2012;9:140-150.

23. Dryden A, Addicott R: Evaluation of a pilot study day for healthcare assistants and social care officers. Int J Palliat Nurs 2009; 15:6-11.

24. Ersek M, Wood BB: Development and evaluation of a nursing assistant computerized education programme. Int $\mathrm{J}$ Palliat Nurs 2008;14:502-509.

25. Holme N, Hart S: Two views of generic care work in 'end of life' care. Res Policy Plan 2007;25:27-41.

26. Denham SA, Meyer MG, Rathbun A, et al.: Knowledge of rural nurses' aides about end-of-life care. Fam Community Health 2006;29:229-241.

27. Wholihan D, Anderson R: Empowering nursing assistants to improve end-of-life care. J Hosp Palliat Nurs 2013;15:24-32.

28. Kaasalainen S, Brazil K, Kelley ML: Building capacity in palliative care for personal support workers in long-term care through experiential learning. Int J Older People Nurs 2014;9:151-158.

29. Farrington CJT: Blended e-learning and end of life care in nursing homes: A small-scale mixed-methods case study. BMC Palliat Care 2014;13:1-16.

30. Dobie J, Plumb M, Shepard S: End of life care education to care home staff: An evaluation. Nurs and Res Care 2016; 18:369-374.

31. Wen A, Gatchell G, Tachibana Y, et al.: A palliative care educational intervention for frontline nursing home staff: The IMPRESS project. J Geron Nurs 2012;38:20-25.

32. Potter G, Pesut B, Hooper BP, Erbacker L: Team-based education in a palliative approach for rural nurses and unlicensed care providers. J Contin Educ Nurs 2015;46:279-288.

33. Finnerty ML, Gregory CA: Impact of a palliative care nursing educational program in a veterans administration medical center. J Hosp Palliat Nurs 2010;12:370-377.

34. Hockley J: Learning, support and communication for staff in care homes: Outcomes of reflective debriefing groups in two care homes to enhance end-of-life care. Int J Older People Nurs 2014;9:118-130.

35. Pesut B, Potter G, Stajduhar K, et al.: Palliative approach to education for rural nurses and health care workers: A mixed method study. Int J Palliat Nurs 2015;21:142-151.

36. Pesut B, McLean T, Reimer-Kirkham S, et al.: Educating registered nursing and healthcare assistant students in community-based supportive care of older adults: A mixed methods study. Nurse Educ Today 2015;35:e90-e96.

37. Connolly M, Charnley K, Regan J: A review of palliative care competence frameworks: Prepared for the palliative care competency framework development project steering group. 2012. http://aiihpc.org/wp-content/uploads/2014/12/ Palliative-Care-Competence-Framework-Report-ProjectGroup.pdf (last accessed June 23, 2017).

38. Canadian Hospice Palliative Care Association: Applying a Model to Guide Hospice Palliative Care: An Essential Companion Toolkit for Planners, Policy Makers, Caregivers, Educators, Managers, Administrators and Researchers. To be used in conjunction with A Model to Guide Hospice Palliative Care: Based on National Principles and Norms of Practice. Ottawa, ON. 2005. www.chpca.net/ media/7458/Applying_a-Model-to-Guide-Hospice-PalliativeCare-Toolkit.pdf (last accessed June 23, 2017).

39. Canadian Hospice Palliative Care A: The Way Forward National Framework: A Roadmap for an Integrated Pallia- tive Approach to Care. 2015. www.hpcintegration.ca/media/ 60044/TWF-framework-doc-Eng-2015-final-April1.pdf (last accessed June 23, 2017).

40. Canadian Hospice Palliative Care Association: Canadian Hospice Palliative Care Nursing Standards of Practice. 2014. www.chpca.net/media/7505/Canadian_Hospice_Palliative_ Care_Nursing_Standards_2009.pdf (last accessed June 23, 2017).

41. Canadian Nurses Association: Certification: https://cnaaiic.ca/en/certification (last accessed June 23, 2017).

42. Canadian Association Schools of Nursing: Palliative and End-of-Life Care: Entry to Practice Competencies and Indicators for Registered Nurses. Ottawa, ON: Canadian Association Schools of Nursing, 2010. http://casn.ca/wpcontent/uploads/2014/12/PEOLCCompetenciesandIndicators En1.pdf (last accessed June 23, 2017).

43. The Association of Canadian Community Colleges, Educators CAoCC: Canadian Educational Standards for Personal Care Providers. www.collegesinstitutes.ca/wp-content/ uploads/2014/05/Reference-Guide_Canadian-EducationalStandards-for-Personal-Care-Providers_ACCC.pdf (last accessed June 23, 2017).

44. Ministry of Training CaU, Ontario: Personal Support Worker Program Standard. Toronto, Ontario. 2014. www.tcu .gov.on.ca/pepg/audiences/colleges/progstan/health/supwork .html (last accessed June 23, 2017).

45. Murray K: Integrating a Palliative Approach: Essentials for Personal Support Workers: Instructor's Guide. Victoria, BC: Life and Death Matters, 2015. http://lifeanddeath matters.ca/wp-content/uploads/2015/05/Instructors-GuideCanadian-Integrating-a-Palliative-Approach_Essentials-forPersonal-Support-Workers1.pdf (last accessed June 23, 2017).

46. Canadian Hospice Palliative Care Association: Training Manual for Home Support Workers. Ottawa, ON: Author, 2006.

47. Centre for Education and Research on Aging and Health Lakehead University: Quality Palliative Care in Long Term Care Alliance: Personal Support Worker Competencies. Thunder Bay, Ontario, 2012. www.palliativealliance.ca/ assets/files/QPC_LTC_PSW_Compet ency_Brochure_Final_ May_2_2012_V2_1.pdf (last accessed June 23, 2017).

48. Ryan K, Connolly M, Charnley K, et al.: Palliative Care Competence Framwork Steering Group. 2014. www.lenus. ie/hse/handle/10147/322310 (last accessed June 23, 2017).

49. Mayrhofer A, Goodman C, Smeeton N, et al.: The feasibility of a train-the-trainer approach to end of life care training in care homes: An evaluation. BMC Palliat Care 2016;15:11.

50. Booth M, Nash S, Banks C, Springett A: Three approaches to delivering end-of-life education to care homes in a region of south east England. Int J Palliat Nurs 2014;20:27-35.

51. Kortes-Miller K, Habjan S, Kelley ML, Fortier M: Development of a palliative care education program in rural longterm care facilities. J Palliat Care 2007;23:154-162.

52. Ferrell B, Malloy P, Virani R: The End of Life Nursing Education Nursing Consortium project. Ann Palliat Med 2015; 4:61-69.

53. Reimer-Kirkham S, Doane GH, Antifeau E, et al.: Translational Scholarship and a Palliative Approach: Enlisting the knowledge-as-action framework. Adv Nurs Sci 2015;38: 187-202.

54. Hartrick Doane G, Stajduhar K, Causton E, et al.: End-oflife care and interprofessional communication: Not simply a matter of "more". Health and Interprofessional Practice. 2012;1. https://dspace.library.uvic.ca/bitstream/handle/1828/ 4704/End-of-life\%20care\%20and\%20interprofessional\%20 
communication $\% 20-\% 20$ Not $\% 20$ simply $\% 20 \mathrm{a} \% 20$ matter $\% 20$ of $\% 20$ more..pdf? sequence $=1 \&$ isAllowed $=y$ (last accessed June 23, 2017).

55. iPANEL Advisory Board: Dying to Care: How Can We Provide Sustainable Quality Care to Persons Living with Advanced Life Limiting Illness in BC: Recommendations to British Columbia Ministry of Health. Victoria, BC, 2014. www.ipanel.ca/publications-presentations/publications/321dying-to-care (last accessed June 23, 2017).

56. Stajduhar K: Chronic illness, palliative care, and the problematic nature of dying. Can J Nurs Res 2011;43:7-15.

57. Sawatzky R, Porterfield P, Lee J, et al.: Conceptual foundations of a palliative approach: A knowledge synthesis. BMC Palliat Care 2016;15:1-14.
58. Thorne S, Roberts D, Sawatzky R: Unravelling the tensions between chronic disease management and end-of-life planning. Res Theory Nurs Pract 2016;30:91-103.

Address correspondence to: Barbara Pesut, PhD, RN

Canada Research Chair, Health, Ethics and Diversity Faculty of Health and Social Development University of British Columbia, Okanagan 1147 Research Road Kelowna, British Columbia V1V 1 V7 Canada

E-mail: barb.pesut@ubc.ca 